\title{
A importância da ludoterapia na assistência pediátrica
}

\section{The importance of play therapy in pediatric care}

\section{La importancia de la terapia de juego em la atención pediátrica}

Livia Aparecida de Melo Pena ORCID: https://orcid.org/0000-0002-5270-8268 Centro Universitário Estácio de Sergipe, Brasil E-mail: liviapena2011@hotmail.com

Ana Fátima Souza Melo de Andrade ORCID: https://orcid.org/0000-0002-7024-6175 Centro Universitário Estácio de Sergipe, Brasil

E-mail: anafatimamelo@hotmail.com

Weber de Santana Teles

ORCID: https://orcid.org/0000-0003-1770-8278

Centro de Hemoterapia de Sergipe, Brasil

E-mail: arteecura@hotmail.com

Max Cruz da Silva

ORCID: https://orcid.org/0000-0002-6944-5986

Faculdade Pio Décimo, Brasil

E-mail: maxlfi@hotmail.com

Ruth Cristini Torres

ORCID: https://orcid.org/0000-0002-8664-192X Instituto de hematologia e hemoterapia de Sergipe, Brasil

E-mail: ruthcristini@gmail.com

Rute Nascimento da Silva

ORCID: https://orcid.org/0000-0002-2719-1623

Universidade Tiradentes, Brasil

E-mail: silva_rute@hotmail.com

Ângela Maria Melo Sá Barros

ORCID: https://orcid.org/0000-0003-4087-3247

Universidade Federal do Rio de Janeiro, Brasil

E-mail: angelsamelo@hotmail.com

Marcel Vinícius Cunha Azevedo

ORCID: https://orcid.org/0000-0002-5312-3333

Centro Universitário Estácio Sergipe, Brasil E-mail: marcelvinicius49@gmail.com

Alejandra Debbo

ORCID: https://orcid.org/0000-0002-7743-5921 Universidade Federal de Sergipe, Brasil E-mail: aledebbo@hotmail.com

Paulo Celso Curvelo Santos Junior ORCID: https://orcid.org/0000-0001-5834-6782 Universidade Tiradentes, Brasil E-mail: paulo.curvelo.jr@gmail.com

Taíssa Alice Soledade Calasans ORCID: https://orcid.org/0000-0003-0460-4437 Universidade Tiradentes, Brasil E-mail: taissa.asc@gmail.com

André Luiz de Jesus Morais ORCID: https://orcid.org/0000-0003-4889-8297

Centro Universitário Estácio de Sergipe, Brasil E-mail: enfermeiro.andre@ hotmail.com

\section{Resumo}

Objetivo: Analisar as evidencias científicas disponíveis na literatura sobre a importância das práticas ludoterápicas em unidades hospitalares de atendimento pediátrico, apenas no cenário brasileiro. Materiais e Métodos: Estudo de revisão integrativa, com abordagem qualitativa e narrativa, a coleta de dados foi realizada no período de janeiro a junho de 2021. As publicações indexadas foram coletadas nas bases de dados: LILACS, BDENF e SCIELO. Os dados foram tabulados e organizados no Microsoft Excel, e posteriormente realizada uma análise descritiva das informações, e expressas em gráficos e tabelas. Resultados e Discussão: Evidenciado que ainda há uma grande desvalorização desta atividade, tanto pelos profissionais quanto pelas instituições, não fornecendo apoio, investimento ou incentivo para a 
inclusão desta prática na rotina de cuidados da criança. Deste modo, os momentos lúdicos são sempre deixados em segundo plano e muitas vezes o paciente pediátrico acaba adquirindo apenas experiências negativas durante a sua internação. Conclusão: enfatiza-se a necessidade de novos estudos que debatam mais sobre essa temática, a fim de aumentar a atenção do público-alvo e ampliar o número de pesquisas e intervenções mais atualizadas. Sendo necessário a realização de capacitações dos acadêmicos e profissionais da área, para que a Ludoterapia seja vista como algo inerente e inseparável da assistência infantil. Visto que, o lúdico traz benefícios não somente para a criança internada, mas também para o seu acompanhante, para a instituição e para a equipe de saúde que está prestando a assistência, propiciando um atendimento pediátrico mais humano e qualificado.

Palavras-chave: Ludoterapia; Jogos e brinquedos; Criança hospitalizada; Enfermagem pediátrica.

\begin{abstract}
Objective: To analyze the scientific evidence available in the literature on the importance of play therapy practices in pediatric hospital units, only in the Brazilian scenario. Materials and Methods: An integrative review study, with a qualitative and narrative approach, data collection was carried out from January to June 2021. Indexed publications were collected in the following databases: LILACS, BDENF and SCIELO. Data were tabulated and organized in Microsoft Excel, and then a descriptive analysis of the information was performed, and expressed in graphs and tables. Results and Discussion: Evidenced that there is still a great devaluation of this activity, both by professionals and institutions, not providing support, investment or encouragement for the inclusion of this practice in the child care routine. In this way, playful moments are always left in the background and pediatric patients often end up acquiring only negative experiences during their hospital stay. Conclusion: we emphasize the need for new studies that debate more on this topic, in order to increase the attention of the target audience and expand the number of more up-to-date research and interventions. It is necessary to carry out training for academics and professionals in the area, so that play therapy is seen as something inherent and inseparable from child care. Since playful activities bring benefits not only for the hospitalized child, but also for their companion, for the institution and for the health team that is providing assistance, providing a more humane and qualified pediatric care.
\end{abstract}

Keywords: Play therapy; Games and toys; Hospitalized child; Pediatric nursing.

\title{
Resumen
}

Objetivo: Analizar la evidencia científica disponible en la literatura sobre la importancia de las prácticas de terapia de juego en unidades hospitalarias pediátricas, solo en el escenario brasileño. Materiales y Métodos: Se realizó un estudio de revisión integradora, con enfoque cualitativo y narrativo, de recolección de datos de enero a junio de 2021 . Se recolectaron publicaciones indexadas en las siguientes bases de datos: LILACS, BDENF y SCIELO. Los datos se tabularon y organizaron en Microsoft Excel, luego se realizó un análisis descriptivo de la información expresada en gráficos y tablas. Resultados y Discusión: Se evidenció que aún existe una gran devaluación de esta actividad, tanto por parte de profesionales como de instituciones, no brindando apoyo, inversión o estímulo para la inclusión de esta práctica en la rutina del cuidado infantil. De esta forma, los momentos lúdicos siempre quedan en un segundo plano y los pacientes pediátricos muchas veces acaban adquiriendo solo experiencias negativas durante su estancia hospitalaria. Conclusión: destacamos la necesidad de nuevos estudios que debatan más sobre este tema, con el fin de aumentar la atención del público objetivo y ampliar el número de investigaciones e intervenciones más actualizadas. Es necesario realizar una formación para académicos y profesionales del área, para que la terapia de juego sea vista como algo inherente e inseparable del cuidado infantil. Ya que las actividades lúdicas traen beneficios no solo para el niño hospitalizado, sino también para su acompañante, para la institución y para el equipo de salud que lo atiende, brindando una atención pediátrica más humana y calificada.

Palabras clave: Terapia de juego; Juegos y juguetes; Niño hospitalizado; Enfermería pediátrica.

\section{Introdução}

A hospitalização é uma experiência estressante para a criança, uma vez que, durante esse período, a mesma é submetida a procedimentos dolorosos, distanciamento do seu convívio diário e das pessoas de sua confiança, além de se deparar com um cenário desconhecido, ruidoso, movimentado e com presença constante de estranhos. Quando não há humanização ou acolhimento suficiente, o processo de internamento pode se tornar um dos mais traumáticos eventos vivenciados na infância, podendo causar transtornos que permanecem mesmo após a alta hospitalar (Lima et al., 2016).

O lúdico pode ser considerado como um importante meio para compreender comportamentos de crianças que vivenciam o âmbito hospitalar frequentemente, sendo um fator que auxilia na elaboração tratamentos clínicos a partir de brinquedos, jogos, filmes, músicas ou até mesmo interações verbais. (Coelho, 2016). 
Durante a internação a criança pode apresentar sentimentos como medo, sensação de abandono, de punição, ansiedade, dentre outras emoções desagradáveis, que podem desencadear ainda maior sofrimento para ela, e dificuldade para a equipe mediante a necessidade de prestação dos cuidados. Quanto menor a idade e capacidade de entendimento do meio externo, maior a intensidade coma qual a criança será afetada, desencadeando maior comprometimento no tratamento e o no bem-estar físico, psicológico e afetivo (Morais \& Junior, 2016).

Nota-se que as crianças, quando hospitalizadas sentem-se desamparadas e podem apresentar comportamentos regressivos, fobias, alterações no sono e mudanças de comportamento. Entende-se, diante dessa situação, que o investimento de humanização no ambiente hospitalar pediátrico torna-se indispensável a fim de promover ações que permitam a ela sentir-se acolhida, amada e cuidada. Nesse contexto, é de extrema relevância a adoção de estratégias facilitadoras para a sua adaptação no ambiente hospitalar, potencializando a capacidade de enfrentamento da enfermidade, bem como a promoção do fortalecimento de vínculo dos profissionais de saúde com a criança e seus familiares (Bosco et al., 2019).

Brincar é a atividade mais importante da infância, sendo extremamente crucial para o desenvolvimento motor, cognitivo, emocional, biológico e social da criança. É a forma pela qual ela se comunica com o seu meio externo e com as pessoas ao seu redor, uma vez que, é através das brincadeiras, imaginações e fantasias que ela exterioriza e expressa seus sentimentos, ansiedades e frustrações (Silva, Valenciano \&Fujisawa, 2017).

A ludoterapia, definida como a "Terapia do Brincar", é um método de tratamento com abordagem focada principalmente em crianças, onde são realizadas atividades e técnicas dinâmicas em forma de brincadeiras, para que o paciente pediátrico se sinta confortável em processar suas emoções, demonstrar seus medos e ansiedades, além de torná-lo mais tranquilo, confiante, aumentando a sua comunicação verbal e não verbal, e incentivando o sentimento de liberdade (Fioreti, Manzo\&Regino, 2016).

Este tipo de terapia permite que a criança se sinta menos vigiada e mais apta a compartilhar os seus sentimentos com o profissional que realiza a dinâmica lúdica, neste caso, o mesmo precisa se juntar a ela no seu mundo de fantasias, em seu nível. No cenário hospitalar, a aplicação da Ludoterapia transforma-se também em um método benéfico auxiliando a criança na fase de aceitação da internação, deste modo, ela passa a compreender melhor o que está se passando em sua vida e torna-se colaborativa no processo de melhora, confiando na equipe e permitindo a realização dos procedimentos (Monteiro \& Correia, 2016).

Por outro viés os riscos de experiências traumáticas vivenciadas pela criança durante a sua internação, são altíssimos, não suprindo as maiores necessidades básicas durante o período de adoecimento, que é o "brincar". Diante disso, objetivou-se analisar as evidencias científicas disponíveis na literatura sobre a importância das práticas ludoterápicas em unidades hospitalares de atendimento pediátrico, apenas no cenário brasileiro.

Bem como apontar os fatores que ocasionam falha na sua implantação, e as possíveis técnicas e artifícios que podem ser utilizadas nesse contexto de forma prática, fácil e de baixo custo, para que ocorra uma maior inserção dessa ferramenta nestes locais.

\section{Materiais e Métodos}

Trata-se de um estudo de revisão integrativa da literatura, de recorte teórico, com abordagem qualitativa e narrativa. Para a elaboração da pesquisa, foram seguidas as seguintes etapas: identificação do tema, seleção da hipótese, estabelecimento dos critérios de inclusão e exclusão de estudos, definição de dados que seriam extraídos, e finalmente a apresentação da revisão.

Para guiar a pesquisa, formulou-se as seguintes questões: Qual a importância da Ludoterapia nas unidades hospitalares de atendimento pediátrico? Quais os principais empecilhos que dificultam a sua implantação, ou contribuem para a não adesão das práticas lúdicas nestas unidades? Quais as possíveis técnicas e artifícios que podem ser implantados pelos profissionais de saúde de forma prática, fácil e de baixo custo no setor para aumentar o uso destas práticas na assistência pediátrica? 
As publicações indexadas foram coletadas nas seguintes bases de dados: Literatura Latino-Americana e do Caribe em Ciências da Saúde (LILACS), na Base de Dados em Enfermagem (BDENF), e na biblioteca eletrônica Scientific Eletronic Library Online (SCIELO). Foram utilizados os seguintes descritores: Ludoterapia, Jogos e Brinquedos, Criança Hospitalizada e Enfermagem Pediátrica. Foi realizado o cruzamento com o Operador Boleano: AND. A coleta de dados foi realizada no período de janeiro a junho de 2021.

Os critérios de inclusão foram: artigos originais em texto completo disponível para leitura, em língua portuguesa, publicados entre 2016 a 2021; pois o objetivo do estudo ressalta apenas a análise em cenário brasileiro. Foram excluídos todos os estudos que não corresponderam a estes critérios. Elaborou-se também um instrumento para a coleta das informações, a fim de responder as questões norteadoras desta revisão, o mesmo foi composto pelos seguintes itens: título, ano de publicação, periódico, local de origem da pesquisa, objetivo do estudo, principais resultados e conclusão. Após a leitura dos artigos selecionados na íntegra, foi realizada a análise e organização em 4 temáticas, para melhor aproveitamento e discussão do tema.

Os dados foram tabulados e organizados no Programa Microsoft Excel, onde foi realizada uma análise descritiva das informações coletadas, e posteriormente expressos em gráficos e tabelas. Por se tratar de uma pesquisa bibliográfica, foram respeitados os princípios éticos a partir os dados obtidos por meio das bases de dados, também foram seguidas as normas da NBR 10520, que especifica as características exigíveis para a apresentação de citação, a NBR 6023 que estabelece o que será incluído nas referências, e a Lei dos direitos autorais 12.853/13 que dispõe em seu Art. $1^{\circ}$. Esta Lei regula os direitos autorais, entendendo-se sob esta denominação os direitos de autor e os que lhes são conexos (ABNT, 2002).

\section{Resultados e Discussão}

Foi realizada a busca eletrônica inicial com o uso dos descritores "Ludoterapia" e "Criança Hospitalizada" utilizando o cruzamento com o operador boleano "AND”, este procedimento foi repetido em todas as bases de dados citadas na metodologia. Foram identificados 215 artigos, e após a leitura dos títulos, notou-se que a maioria deles se encontravam em todas as bases de dados supracitadas. Após a utilização dos critérios de inclusão, foram filtrados apenas 20 estudos. Destes, 5 foram descartados por não se tratarem de artigos originais, totalizando 15 artigos na amostra final.

Dos estudos selecionados, $40 \%$ (n 6) foram realizados na região Nordeste, $26,6 \%$ (n 4) na região Sul, 20\% (n 3) na região Sudeste, 6,7\% (n 1) na região Norte e 6,7\% (n 1) na região Centro-Oeste (Figura1). Evidenciou-se ainda, que a Revista de Enfermagem UFPE online foi a que mais publicou sobre o tema Ludoterapia, representando 40\% (n 6) da amostra final, seguida da Revista Gaúcha de Enfermagem com 13,3\% (n 2) do total, já os restantes dos artigos (n 7) representaram apenas uma amostra de cada periódico publicado (Figura 2).

Quanto à metodologia utilizada em campo pelos autores, cerca de 1/3 $(33,4 \%)$ optou em realizar entrevista com profissionais da saúde que trabalhavam nas unidades de assistência pediátrica. Entretanto, uma grande parte dos estudos publicados também realizou entrevista com os familiares e com as crianças internadas, visto que, ambas as amostras totalizaram em 26,6\% da porcentagem final. Por fim, apenas duas pesquisas realizaram Ensaio Clínico Randomizado com as crianças (Figura $3)$.

A principal justificativa para a maioria das pesquisas focar em entrevista com profissionais de saúde é relatado em diversos estudos, como o de Martins et al (2016), Silva et al (2019), Paula et al (2019), e Silveira e Picollo (2020), onde os autores enfatizam a importância de ouvir a equipe que presta a assistência direta às crianças e família, visto que, através deles é possível compreender os principais empecilhos que dificultam a implantação de práticas ludoterápicas no ambiente hospitalar infantil, bem como analisar as possíveis sugestões destes profissionais para melhor adaptação do lúdico nestas unidades. 
Tais dados referentes às regiões dos estudos, Distribuição dos estudos com base nas regiões brasileiras de publicações: Figura 1. Distribuição dos estudos conforme revistas que mais publicam sobre temática estudada: Figura 2 - Caracterização da metodologia dos estudos selecionados, respectivamente na Figura 3.

Figura 1 - Distribuição dos estudos com base nas regiões brasileiras de publicações.

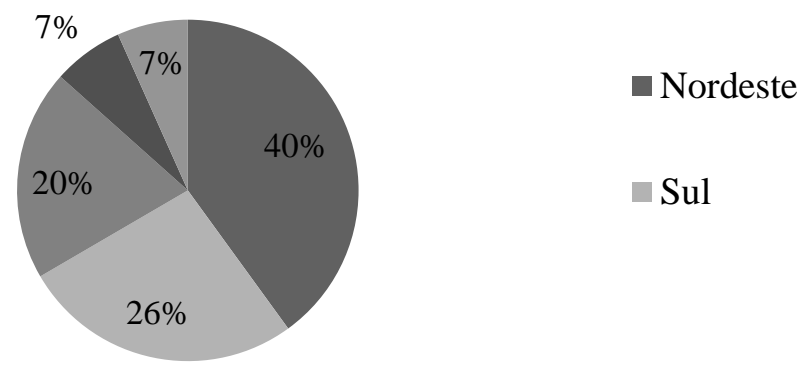

Fonte: Elaboração própria.

Figura 2 - Distribuição dos estudos conforme revistas que mais publicam sobre temática estudada.

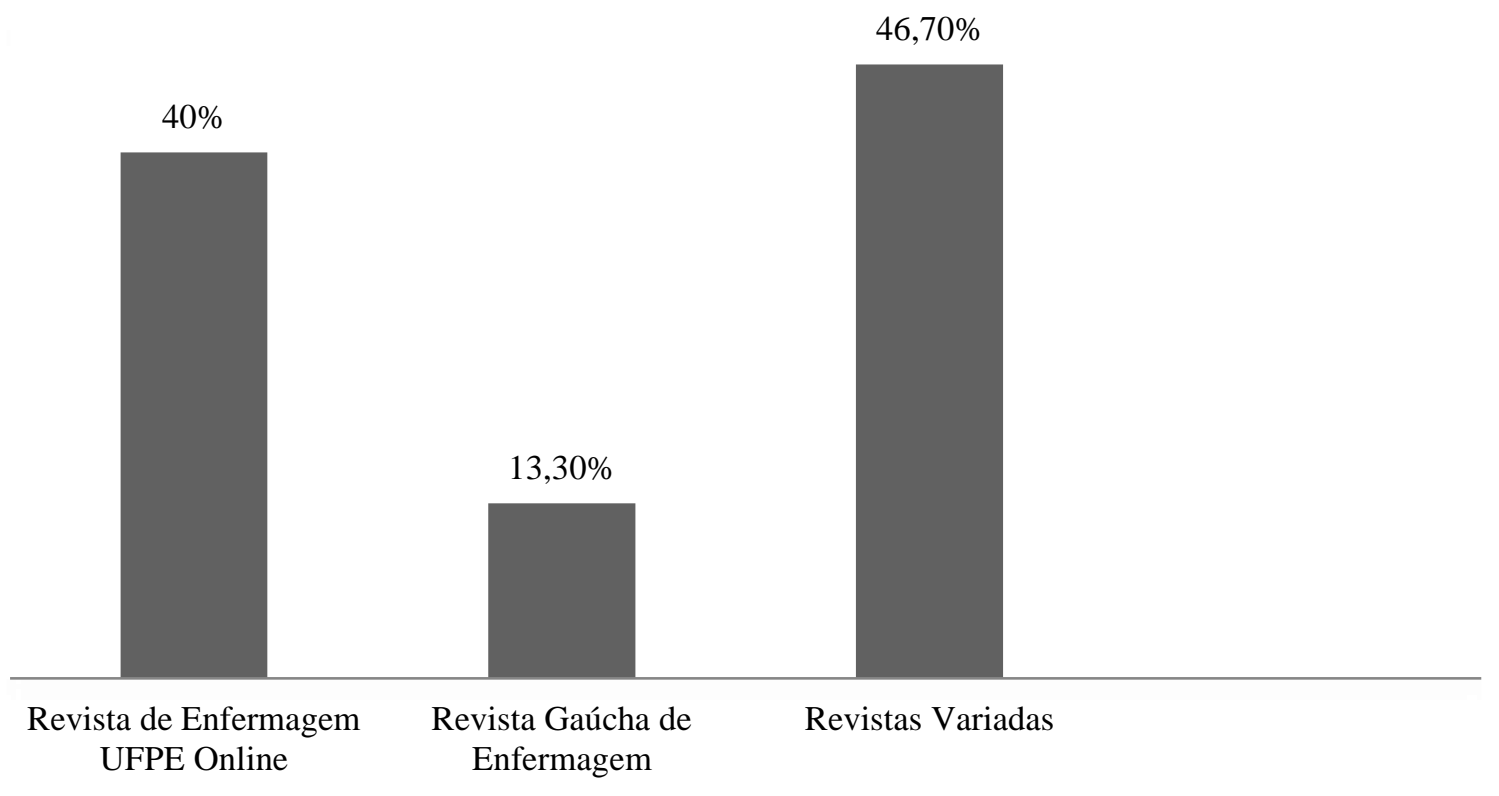

Fonte: Elaboração própria. 
Figura 3 - Caracterização da metodologia dos estudos selecionados

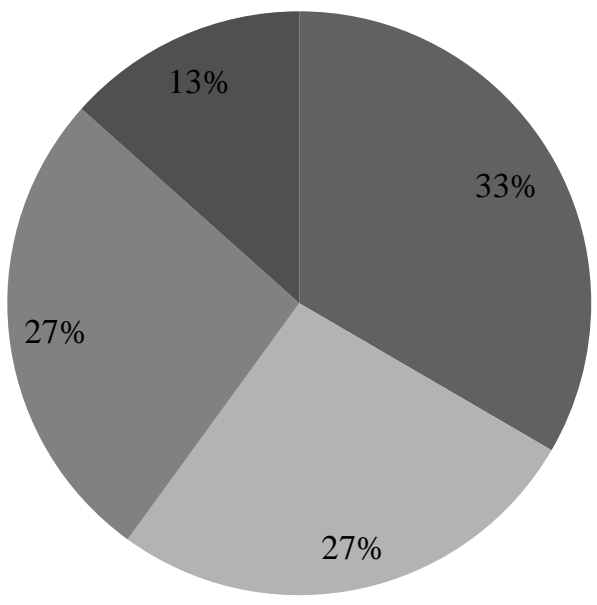

Entrevista com profissionais de saúde

Entrevista com familiares

Entrevista com as crianças

- Ensaio Clínico Randomizado com as crianças

Fonte: Autores.

Para proferir melhor análise, foi elaborádo um quadro sinóptico com título, autores, metodologia e objetivos, o que possibilita a compreensão e síntese dos conteúdos abordados com relação ao tema proposto. Conforme demonstrado no Quadro 1.

Quadro 1 - Quadro sinóptico com a caracterização dos estudos selecionados.

\begin{tabular}{|c|c|c|c|c|}
\hline Artigo & Autor/Ano & $\begin{array}{l}\text { Local de } \\
\text { realização }\end{array}$ & Objetivo & Principais Resultados \\
\hline $\begin{array}{l}\text { Humanização } \\
\text { Hospitalar na } \\
\text { pediatria: } \\
\text { Projeto } \\
\text { enfermeiros da } \\
\text { alegria }\end{array}$ & $\begin{array}{l}\text { Bosco et al. } \\
(2019)\end{array}$ & Recife & $\begin{array}{l}\text { Relatar sobre a relevância } \\
\text { da humanização hospitalar } \\
\text { na Pediatria por meio da } \\
\text { prática acadêmica em } \\
\text { terapias lúdicas }\end{array}$ & $\begin{array}{l}\text { Projeto com iniciativas como a do Enfermeiros da } \\
\text { Alegria, que possibilita as brincadeiras infantis no } \\
\text { ambiente hospitalar, proporcionam novos significados } \\
\text { ao cuidar e contribuem na humanização da assistência } \\
\text { pediátrica. }\end{array}$ \\
\hline $\begin{array}{l}\text { A utilização do } \\
\text { lúdico no cenário } \\
\text { da } \\
\text { hospitalização } \\
\text { pediátrica }\end{array}$ & $\begin{array}{l}\text { Silva el al. } \\
(2019)\end{array}$ & Alagoas & $\begin{array}{l}\text { Descrever a percepção da } \\
\text { equipe multiprofissional } \\
\text { sobre a utilização do lúdico } \\
\text { e dos fatores que interferem } \\
\text { na sua prática no contexto } \\
\text { do cuidado à criança } \\
\text { hospitalizada }\end{array}$ & $\begin{array}{l}\text { Revela-se que os profissionais percebem como o lúdico } \\
\text { ajuda a modificar o ambiente hospitalar, os sentimentos } \\
\text { e o processo de comunicação com a criança, além de } \\
\text { influenciar na adesão às terapêuticas, à socialização, à } \\
\text { promoção de vínculos e à colaboração com a equipe, } \\
\text { ainda que nem todos se sintam preparados para } \\
\text { incorporá-lo à sua rotina de trabalho. }\end{array}$ \\
\hline $\begin{array}{lr}\text { Estratégias } & \\
\text { lúdicas } & \text { no } \\
\text { cuidado } & \text { de } \\
\text { enfermagem } & \text { à } \\
\text { criança } & \\
\text { hospitalizada } & \end{array}$ & $\begin{array}{l}\text { Paula et al. } \\
\text { (2019) }\end{array}$ & Rio de Janeiro & $\begin{array}{l}\text { Analisar o uso de estratégias } \\
\text { lúdicas no cuidado à criança } \\
\text { hospitalizada na perspectiva } \\
\text { da equipe de Enfermagem }\end{array}$ & $\begin{array}{l}\text { Avalia-se que os fatores limitantes precisam ser } \\
\text { superados para a garantia do atendimento integral às } \\
\text { crianças hospitalizadas, considerando que o brincar é } \\
\text { um direito garantido legalmente, além de contribuir } \\
\text { para a recuperação mais prazerosa e para o pleno } \\
\text { desenvolvimento infantil. }\end{array}$ \\
\hline $\begin{array}{l}\text { A importância } \\
\text { do lúdico no } \\
\text { context da } \\
\text { hospitalização } \\
\text { infantil }\end{array}$ & $\begin{array}{l}\text { Silva et al. } \\
(2018)\end{array}$ & Bahia & $\begin{array}{l}\text { Analisar a importância do } \\
\text { lúdico no contexto da } \\
\text { hospitalização infantil }\end{array}$ & $\begin{array}{l}\text { Evidenciou-se que, de fato, o lúdico tem sua } \\
\text { importância dentro do contexto da hospitalização } \\
\text { infantil, uma vez que traz benefícios não somente para } \\
\text { a criança hospitalizada, mas, também, para a família e } \\
\text { a equipe de saúde, além de possibilitar um cuidado mais } \\
\text { humanizado. }\end{array}$ \\
\hline $\begin{array}{l}\text { Percepção dos } \\
\text { acompanhantes } \\
\text { das crianças } \\
\text { hospitalizadas } \\
\text { acerca do }\end{array}$ & $\begin{array}{l}\text { Silva et al. } \\
\text { (2018) }\end{array}$ & Recife & $\begin{array}{l}\text { Identificar a percepção dos } \\
\text { acompanhantes das crianças } \\
\text { hospitalizadas com relação } \\
\text { às atividades lúdicas }\end{array}$ & $\begin{array}{l}\text { Considerou-se primordial que os profissionais atuantes } \\
\text { na Pediatria desenvolvam estratégias para a utilização } \\
\text { do brinquedo terapêutico, melhorando a assistência } \\
\text { oferecida e como contribuição, proporcionando o } \\
\text { atendimento mais humano e qualificado na área }\end{array}$ \\
\hline
\end{tabular}




\begin{tabular}{|c|c|c|c|c|}
\hline $\begin{array}{l}\text { brinquedo } \\
\text { terapêutico }\end{array}$ & & & & \\
\hline $\begin{array}{l}\text { O conhecimento } \\
\text { dos pais quanto } \\
\text { ao processo do } \\
\text { cuidar por meio } \\
\text { do brincar }\end{array}$ & $\begin{array}{l}\text { Sabino et al. } \\
(2018)\end{array}$ & Manaus & $\begin{array}{l}\text { Verificar a percepção dos } \\
\text { pais e/ou responsáveis } \\
\text { legais de crianças } \\
\text { hospitalizadas sobre a } \\
\text { atividade do brincar como } \\
\text { uma dimensão do cuidado } \\
\text { de Enfermagem }\end{array}$ & $\begin{array}{l}\text { Há a extrema necessidade de capacitar e sensibilizar os } \\
\text { profissionais para utilizar o brincar em sua prática } \\
\text { assistencial }\end{array}$ \\
\hline $\begin{array}{l}\text { Percepção da } \\
\text { equipe } \\
\text { enfermagem } \\
\begin{array}{l}\text { sobre } \\
\text { abordagem }\end{array} \\
\text { lúdica à criança } \\
\text { hospitalizada }\end{array}$ & $\begin{array}{l}\text { Falke, } \\
\text { Milbrath \& } \\
\text { Freitag. } \\
(2017)\end{array}$ & $\begin{array}{l}\text { Rio Grande do } \\
\text { Sul }\end{array}$ & $\begin{array}{l}\text { Conhecer a percepção da } \\
\text { equipe de enfermagem } \\
\text { sobre a abordagem lúdica à } \\
\text { criança hospitalizada. }\end{array}$ & $\begin{array}{l}\text { Observou-se que a equipe de enfermagem não possui o } \\
\text { preparo técnico-científico para utilizar a abordagem } \\
\text { lúdica na prestação de assistência de enfermagem, visto } \\
\text { que além de alguns desconhecerem o conceito e as } \\
\text { técnicas aplicadas à ludoterapia, esse tema teve escasso } \\
\text { ou nenhuma abordagem na formação acadêmica ou } \\
\text { profissional dos entrevistados. }\end{array}$ \\
\hline $\begin{array}{l}\text { Influência do } \\
\text { Brinquedo } \\
\text { Terapêutico na } \\
\text { ansiedade de } \\
\text { crianças } \\
\text { escolares } \\
\text { hospitalizadas: } \\
\text { Ensaio clínico }\end{array}$ & $\begin{array}{l}\text { Silva et al. } \\
(2017) \text {. }\end{array}$ & São Paulo & $\begin{array}{l}\text { Avaliar os efeitos da } \\
\text { aplicação da técnica do } \\
\text { Brinquedo Terapêutico } \\
\text { Dramático (BTD) no grau } \\
\text { de ansiedade em crianças } \\
\text { escolares hospitalizadas }\end{array}$ & $\begin{array}{l}\text { Participaram do estudo } 28 \text { crianças. A maioria das } \\
\text { crianças de ambos os grupos }(75 \%) \text { apresentou } \\
\text { classificação de baixo grau de ansiedade, sendo o } \\
\text { escore médio do instrumento CD: H no grupo } \\
\text { intervenção de } 73,9 \text { e no grupo controle de } 69,4 \text {, sem } \\
\text { diferença significativa. As crianças submetidas ao BTD } \\
\text { apresentaram o mesmo grau de ansiedade que as do } \\
\text { grupo controle. Entretanto, sugere-se que novos } \\
\text { estudos sejam realizados com maior número de } \\
\text { crianças em variados cenários da hospitalização. }\end{array}$ \\
\hline $\begin{array}{l}\text { A hospitalização } \\
\text { infantil: } \\
\text { Vivências de } \\
\text { crianças a partir } \\
\text { de } \\
\text { representações } \\
\text { gráficas }\end{array}$ & $\begin{array}{l}\text { Costa } \quad \& \\
\text { Morais } \\
(2017)\end{array}$ & Recife & $\begin{array}{lcr}\text { Analisar a vivência } & \text { da } \\
\text { criança sobre o processo de } \\
\text { hospitalização } & \text { e } & \text { as } \\
\text { alterações } & & \text { no } \\
\text { comportamento do } & \text { ser } \\
\text { infantil frente } & \text { à } & \text { sua } \\
\text { hospitalização } & & \end{array}$ & $\begin{array}{l}\text { Surge a necessidade de realizar o esclarecimento para } \\
\text { as crianças sobre a realização dos procedimentos, para } \\
\text { que as mesmas sejam emocionalmente preparadas para } \\
\text { conviver nesse ambiente e ter participação ativa junto à } \\
\text { família durante a hospitalização. }\end{array}$ \\
\hline $\begin{array}{l}\text { Contribuição do } \\
\text { brinquedo } \\
\text { terapêutico } \\
\text { estruturado em } \\
\text { um modelo de } \\
\text { cuidado de } \\
\text { enfermagem } \\
\text { para crianças } \\
\text { hospitalizadas }\end{array}$ & $\begin{array}{l}\text { Caleffi et al. } \\
(2016) \text {. }\end{array}$ & Santa Catarina & $\begin{array}{l}\text { Analisar como o Brinquedo } \\
\text { Terapeutico estruturado em } \\
\text { um Modelo de Cuidado de } \\
\text { Enfermagem contribui no } \\
\text { cuidado a criança } \\
\text { hospitalizada. }\end{array}$ & $\begin{array}{l}\text { Conclui-se que aplicar o BT estruturado em um } \\
\text { Modelo de Cuidado pode contribuir para um cuidado } \\
\text { de enfermagem sistematizado e especializado. } \\
\text { Verificou-se que ao brincar a visão do ambiente } \\
\text { hospitalar e dos profissionais torna-se menos negativa, } \\
\text { diminuindo os prejuízos de uma hospitalização mal } \\
\text { vivenciada. E, com a utilização do BT percebeu-se } \\
\text { que as crianças podem vir a compreender a } \\
\text { necessidade da internação e poder vivenciar este } \\
\text { momento de forma mais tranquila. }\end{array}$ \\
\hline $\begin{array}{l}\text { Brinquedo } \\
\text { Terapêutico no } \\
\text { procedimento de } \\
\text { punção venosa: } \\
\text { Estratégia para } \\
\text { reduzir } \\
\text { alterações } \\
\text { comportamentai } \\
\text { s }\end{array}$ & $\begin{array}{l}\text { Lemos et al. } \\
(2016) \text {. }\end{array}$ & Cariri - Ceará & $\begin{array}{l}\text { Comparar as reações } \\
\text { comportamentais } \\
\text { manifestadas pela criança } \\
\text { frente ao preparo para } \\
\text { punção venosa antes e após } \\
\text { o uso do BTI }\end{array}$ & $\begin{array}{l}\text { Após o uso do BTI, observou-se uma redução na } \\
\text { frequência de variáveis comportamentais que indicam } \\
\text { menor adaptação ao procedimento, com significância } \\
\text { estatística em especial para: "Solicita a presença } \\
\text { Materna" e "Evita olhar para o Profissional" (p<0,001). } \\
\text { A realização das sessões também potencializou a } \\
\text { frequência de, praticamente, todos os comportamentos } \\
\text { associados a uma melhor aceitação ao preparo ou } \\
\text { realização da punção venosa. O BTI constitui relevante } \\
\text { intervenção para a enfermagem pediátrica, sendo } \\
\text { necessário, para sua aplicação sistematizada, articular } \\
\text { ações que visem uma maior sensibilização dos órgãos } \\
\text { gestores dos serviços de pediatria, maior capacitação } \\
\text { dos profissionais envolvidos e melhor abordagem do } \\
\text { ensino do brinquedo terapêutico nos cursos de } \\
\text { graduação de enfermagem. }\end{array}$ \\
\hline $\begin{array}{l}\text { Repercussões da } \\
\text { clownterapia no } \\
\text { processo de } \\
\text { hospitalização } \\
\text { da criança }\end{array}$ & $\begin{array}{l}\text { Martins et al. } \\
(2016) \text {. }\end{array}$ & Rio de Janeiro & $\begin{array}{l}\text { Analisar as repercussões da } \\
\text { Clownterapia no processo } \\
\text { de hospitalização da criança }\end{array}$ & $\begin{array}{l}\text { A Clownterapia mostra-se como facilitadora das } \\
\text { práticas específicas da enfermagem no aspecto } \\
\text { individual e coletivo das crianças hospitalizadas, } \\
\text { trazendo a perspectiva de promoção da saúde para estes } \\
\text { sujeitos. }\end{array}$ \\
\hline $\begin{array}{l}\text { A ludoterapia } \\
\text { como ferramenta } \\
\text { na assistência }\end{array}$ & $\begin{array}{l}\text { Santos et al. } \\
(2016) \text {. }\end{array}$ & São Paulo & $\begin{array}{l}\text { O objetivo foi descrever a } \\
\text { ludoterapia como parte do } \\
\text { tratamento e recuperação de } \\
\text { pessoas hospitalizadas. }\end{array}$ & $\begin{array}{l}\text { O tratamento através do lúdico contribuiu para o bem- } \\
\text { estar dos pacientes internados, corroborando para um } \\
\text { atendimento humanizado. Os pacientes pediátricos } \\
\text { modificaram sua concepção sobre a internação, pois }\end{array}$ \\
\hline
\end{tabular}




\begin{tabular}{|c|c|c|c|c|}
\hline $\begin{array}{l}\text { humanizada de } \\
\text { enfermagem }\end{array}$ & & & & $\begin{array}{l}\text { diferente do que a maioria imagina brincar não é só } \\
\text { passar o tempo como forma de distrair o paciente de um } \\
\text { tratamento doloroso, mas também prestar uma } \\
\text { assistência digna de forma integral. O lúdico além de } \\
\text { auxiliar o paciente para enfrentar a patologia, atua na } \\
\text { melhora da qualidade de vida e proporciona um } \\
\text { completo bem-estar físico e mental. }\end{array}$ \\
\hline $\begin{array}{l}\text { A ludoterapia e a } \\
\text { criança } \\
\text { hospitalizada na } \\
\text { perspectiva dos } \\
\text { pais }\end{array}$ & $\begin{array}{l}\text { Fioreti, } \\
\text { Manzo \& } \\
\text { Regino. } \\
\text { (2016). }\end{array}$ & Minas Gerais & $\begin{array}{l}\text { Analisar o uso do brincar na } \\
\text { assistência à criança } \\
\text { hospitalizada na perspectiva } \\
\text { dos pais. }\end{array}$ & $\begin{array}{l}\text { Os achados evidenciaram que o brincar é instrumento } \\
\text { de grande valor para minimizar o estresse da internação } \\
\text { e contribuir para melhor adaptação da criança ao } \\
\text { ambiente hospitalar. O mesmo traz benefícios } \\
\text { referentes à promoção do bem-estar, diversão, redução } \\
\text { da dor e socialização durante a hospitalização. } \\
\text { Concluiu-se, dessa maneira, que a utilização do brincar } \\
\text { pode ser muito benéfica na rotina da Pediatria, } \\
\text { favorecendo um cuidado mais humanizado e integral, } \\
\text { além da possibilidade de diminuir os prejuízos no } \\
\text { desenvolvimento da criança, causados pela experiência } \\
\text { da hospitalização. }\end{array}$ \\
\hline $\begin{array}{l}\text { Brinquedo } \\
\text { Terapêutico na } \\
\text { assistência à } \\
\text { criança } \\
\text { hospitalizada na } \\
\text { voz dos } \\
\text { profissionais de } \\
\text { enfermagem }\end{array}$ & $\begin{array}{l}2020 \text { Silveira } \\
\& \text { Picollo }\end{array}$ & $\begin{array}{l}\text { Rio Grande do } \\
\text { Sul }\end{array}$ & $\begin{array}{l}\text { Identificar o conhecimento } \\
\text { da equipe de enfermagem } \\
\text { sobre a utilização do } \\
\text { Brinquedo Terapêutico na } \\
\text { assistência à criança } \\
\text { hospitalizada em uma } \\
\text { Unidade Pediátrica. }\end{array}$ & $\begin{array}{l}\text { Os profissionais de enfermagem percebem os } \\
\text { benefícios do brincar no ambiente pediátrico, todavia as } \\
\text { sessões de brinquedo terapêutico não são realizadas } \\
\text { pelo desconhecimento. A brinquedoteca é utilizada } \\
\text { pelas crianças e seus familiares acompanhantes, outras } \\
\text { vezes por projetos que ocorrem na unidade. Sugere-se } \\
\text { o desenvolvimento de atividades educativas, oficinas } \\
\text { sobre o lúdico e a aplicação da sessão de brinquedo } \\
\text { terapêutico. Recomenda-se o desenvolvimento de } \\
\text { protocolos que incluam o brinquedo no processo de } \\
\text { cuidado, a fim de que o brincar faça parte da assistência } \\
\text { de enfermagem no ambiente pediátrico. }\end{array}$ \\
\hline $\begin{array}{l}\text { O brinquedo } \\
\text { terapêutico } \\
\text { instrucional } \\
\text { como ferramenta } \\
\text { na assistência } \\
\text { oncológica } \\
\text { infantil }\end{array}$ & $\begin{array}{l}\text { Silva et al. } \\
(2020) \text {. }\end{array}$ & Pará & $\begin{array}{l}\text { Descrever as vivências de } \\
\text { acadêmicos de enfermagem } \\
\text { sobre } \\
\text { atividades educativas } \\
\text { assistenciais realizadas em } \\
\text { um hospital oncológico } \\
\text { infantil por meio do uso de } \\
\text { brinquedos terapêuticos } \\
\text { instrucionais. }\end{array}$ & $\begin{array}{l}\text { O brinquedo terapêutico mostrou-se um eficiente } \\
\text { dispositivo para o preparo e desenvolvimento social, } \\
\text { intelectual e emocional da criança até mesmo durante } \\
\text { a internação, com a redução de tensão e a mitigação de } \\
\text { sentimentos como medo e insegurança. }\end{array}$ \\
\hline $\begin{array}{l}\text { A importância } \\
\text { do brincar } \\
\text { durante a } \\
\text { internação } \\
\text { hospitalar: um } \\
\text { relato de } \\
\text { experiência. }\end{array}$ & $\begin{array}{l}\text { Júnior et al. } \\
\text { (2019). }\end{array}$ & Pará & $\begin{array}{l}\text { Relatar a experiência de } \\
\text { alunos do } 7^{\circ} \text { semestre do } \\
\text { curso de graduação em } \\
\text { enfermagem sobre a } \\
\text { importância do brincar para } \\
\text { crianças e seus familiares } \\
\text { durante a internação } \\
\text { hospitalar, através de um } \\
\text { estudo descritivo, tipo } \\
\text { relato de experiência. }\end{array}$ & $\begin{array}{l}\text { O brincar faz toda diferença na recuperação do paciente } \\
\text { pediátrico em relação a sua melhora do quadro clinico, } \\
\text { podendo evitar estresse, depressão ou isolamento } \\
\text { daquela criança. }\end{array}$ \\
\hline $\begin{array}{l}\text { Contribuições } \\
\text { Da Ludoterapia } \\
\text { Para Crianças } \\
\text { Hospitalizadas. }\end{array}$ & $\begin{array}{l}\text { Silva et al. } \\
(2019) \text {. }\end{array}$ & Alagoas. & $\begin{array}{l}\text { Investigar na literatura as } \\
\text { contribuições da } \\
\text { ludoterapia no tratamento } \\
\text { de crianças hospitalizadas. } \\
\text { Trata-se de um estudo de } \\
\text { revisão da literatura, com } \\
\text { abordagem descritiva. }\end{array}$ & $\begin{array}{l}\text { Através da ludoterapia as crianças hospitalizadas } \\
\text { puderam se comunicar, interagir, e expressar as suas } \\
\text { emoções sobre o processo de adoecimento. Também } \\
\text { percebeu uma melhor aderência ao tratamento de } \\
\text { câncer, juntamente do aumento da autoestima após o } \\
\text { brincar, deixando as crianças e os seus familiares } \\
\text { alegres. Portanto, é de suma relevância a ludoterapia no } \\
\text { processo de hospitalização, pois reduz os impactos } \\
\text { psicológicos do adoecimento trazendo novas } \\
\text { perspectiva de cuidado a criança. }\end{array}$ \\
\hline $\begin{array}{l}\text { Therapeutic play } \\
\text { to prepare } \\
\text { children for } \\
\text { invasive } \\
\text { procedures: a } \\
\text { systematic } \\
\text { review. }\end{array}$ & $\begin{array}{l}\text { Silva et al. } \\
\text { (2017). }\end{array}$ & Pernambuco. & $\begin{array}{l}\text { Revisar, de rorma } \\
\text { sistemática, as evidências } \\
\text { em relac,ão à eficácia do } \\
\text { uso do brinquedo } \\
\text { terapêutico sobre o o } \\
\text { comportamento e a } \\
\text { ansiedade de crianc, as } \\
\text { submetidas a procedimentos } \\
\text { invasivos }\end{array}$ & $\begin{array}{l}\text { A maioria dos estudos mostrou que a intervenção com } \\
\text { brinquedo terapêutico promove redução no nível de } \\
\text { ansiedade e favorece um comportamento de } \\
\text { colaboração e aceitação do procedimento invasivo. }\end{array}$ \\
\hline
\end{tabular}




\begin{tabular}{|c|c|c|c|c|}
\hline $\begin{array}{l}\text { Recusa Escolar: } \\
\text { um Estudo de } \\
\text { Caso em } \\
\text { Ludoterapia } \\
\text { Comportamental }\end{array}$ & $\begin{array}{l}\text { Coelho, et al. } \\
(2016) \text {. }\end{array}$ & $\begin{array}{l}\text { Distrito } \\
\text { Federal }\end{array}$ & $\begin{array}{l}\text { Contextualizar a aplicação } \\
\text { do conceito de lúdico em } \\
\text { ludoterapia } \\
\text { comportamental. }\end{array}$ & $\begin{array}{l}\text { Modelo de tomada de decisão clínica descrevem como } \\
\text { o psicólogo analisa as interações da criança com seu } \\
\text { ambiente. Tal modelo de tomada de decisão deve ser } \\
\text { capaz de incluir as características principais do conceito } \\
\text { de lúdico presentes na teoria de Dember-Earl. }\end{array}$ \\
\hline
\end{tabular}

Fonte: Autores.

Foram encontradas similaridades de temáticas abordadas nos estudos e, assim, desenvolveram-se quatro categorias temáticas (Quadro 2):“A importância e os benefícios da terapia lúdica para a criança hospitalizada”; "A utilização da brinquedoteca e dos brinquedos terapêuticos no contexto hospitalar";" Dificuldades e empecilhos que interferem na implantação da Ludoterapia" e "Estratégias para a introdução do lúdico no ambiente pediátrico."

Quadro 2 - Apresentação das respectivas categorias metodológicas.

\begin{tabular}{|l|}
\hline A importância e os benefícios da terapia lúdica para a criança hospitalizada \\
\hline A utilização da brinquedoteca e dos brinquedos terapêuticos no contexto hospitalar \\
\hline Dificuldades e empecilhos que interferem na implantação da Ludoterapia \\
\hline Estratégias para a introdução do lúdico no ambiente pediátrico \\
\hline
\end{tabular}

Fonte: Autores.

\section{A importância e os benefícios da terapia lúdica para a criança hospitalizada}

Durante a brincadeira a criança recria o mundo ao seu redor, seu conhecimento se amplia, e ela expressa tudo que sente e vê durante essa interação, estabelecendo um vínculo entre o real e o imaginário. Através do faz-de-conta ela trabalha o processo de imaginação e organiza seus pensamentos recriando vivências simbólicas, elaborando a sua própria realidade. Portanto, a brincadeira é considerada uma atividade humana e sociocultural, possibilitando que ela vivencie um momento de aprendizagem e incorporação de papéis no contexto em que se insere, elaborando seus primeiros conceitos e exteriorizando o que pensa sobre o mundo em que vive (Caleffiet al., 2016).

O brincar no ambiente hospitalar torna-se uma fuga da realidade para a criança, um momento depaz e bem-estar que possibilita uma breve distração da sua rotina tão estressante dentro do hospital, e consequentemente colabora para a melhora em seu tratamento. Por isso, é muito importante que haja nos setores pediátricos uma área destinada exclusivamente para recreação, jogos, pinturas, músicas e filmes. Este local influencia positivamente na recuperação da criança internada, refletindo também na satisfação dos seus familiares, e dos trabalhadores envolvidos, que irão perceber o resultando na execução do seu trabalho (Sabino et al., 2018).

No transcorrer da hospitalização, diversos fatores de estresse, como: longo período de internação, múltiplos procedimentos invasivos e dolorosos, mudança do convívio habitual, contato recorrente com estranhos e a ansiedade dos pais, podem ocasionar traumas na criança, uma vez que expõe a mesma a resultados negativos de curto e longo prazo. Salienta-se que, nesse contexto, as respostas mais comuns a estes eventos incluem regressão, ansiedade, apatia, fobias, distúrbios do sono, dentre outros (Silva et al., 2019).

Segundo Júnior et al. (2019), o avanço clínico é notório quando existe a participação ativa entre a equipe de saúde e os familiares, elevando a melhora durante as medidas profiláticas e também a aceitação da doença de forma mais branda para os pais e responsáveis.

Neste caso, o lúdico emerge como uma estratégia fundamental para se promover momentos de descontração e diversão às crianças. Permite-se através desta prática, que os profissionais de saúde, incluindo especialmente os da enfermagem, atuem de forma humanizada, atendendo às necessidades recreativas e terapêuticas específicas destes pacientes, respeitando a 
importância mesmo no contexto hospitalar, bem como a possibilidade de utilizar esse momento como uma forma privilegiada de aproximação e comunicação com elas (Paula et al., 2019).

Silva et al. (2017) afirma que a necessidade da criança em brincar não deve ser ignorada quando estas se encontram doentes e/ou em âmbito hospitalar, quando estas práticas são consideradas, a criança se sentirá segura, confortável e aceitará melhor intervenções que precisam ser realizadas.

Através da Ludoterapia, a criança passa a "aceitar" o profissional de saúde que lhe está prestando assistência, porque o medo da mesma com relação ao profissional de jaleco branco diminui gradualmente após a aproximação entre ambos. Por meio destas atividades, nota-se também que a atmosfera do ambiente muda, passando de hostil para alegre e mais infantil, as expressões faciais das crianças passam a ser mais alegres, com risos e sorrisos, e a espera pelo retorno das atividades lúdicas traz um ponto positivo a mais: a euforia e a melhora do relacionamento com a equipe de Enfermagem (Silva et al., 2018).

O brincar deve ser utilizado pela equipe de enfermagem preferencialmente em três momentos: durante a rotina diária, no preparo dos procedimentos invasivos e durante a realização de procedimentos dolorosos e desagradáveis. É de suma importância que o profissional tenha sensibilidade com este tipo de público, contribuindo para a amenização do sofrimento resultante da hospitalização. Ressalta-se também que, além dos benefícios terapêuticos, o lúdico funciona como uma ligação entre a criança e o profissional de saúde, caracterizando-se como uma atividade que facilita a comunicação entre ambos e melhora a condução dos objetivos estabelecidos no plano de cuidados (Costa \& Morais, 2017).

Assim, a ludoterapia atua de forma eficaz oferecendo conforto tanto para o acompanhante, quanto para o hospitalizado, uma vez que acontece o envolvimento nas atividades ludoterápicas (Silva et al, (2020).

\section{A utilização da brinquedoteca e dos brinquedos terapêuticos no contexto hospitalar}

O Brinquedo Terapêutico (BT) é todo e qualquer brinquedo utilizado com a finalidade de aliviar a ansiedade da criança, servindo muitas vezes para instruir sobre a sua patologia e os procedimentos que serão realizados na mesma, facilitando assim a colaboração e maior confiança na equipe durante o período de internação. É uma ferramenta fundamental aos profissionais de saúde que trabalham em unidades pediátricas, caracterizando-se como um recurso lúdico que, de forma indireta, favorece uma comunicação mais adequada entre a criança e o adulto (Falke\&Freitag, 2017).

O ambiente hospitalar e a forma como ele é planejado influenciam no comportamento e grau de ansiedade da criança frente à internação, onde o mesmo é visto como um local hostil, fechado, que gera medo e insegurança, principalmente devido a sua estrutura e a grande utilização do branco que é tão típico do ambiente hospitalar. Neste contexto, a brinquedoteca hospitalar expressa a necessidade de ser projetado como um local colorido, divertido, interativoe atraente, a fim de estimular o prazer da criança de brincar sozinha ou em grupo (Lemos et al., 2016).

A brinquedoteca é umlocal reservado dentro do hospital onde o paciente pediátrico pode brincar com suas fantasias, desejos, e realizar tudo o que ele quiser no mundo do faz-de-conta. Entretanto, este ambiente também pode ser utilizado para intervenções educativas, como contação de histórias, teatro de fantoches, atividades de pintura e colagem, comemorações de datas festivas, e dinâmicas que podem ser realizadas tanto com as crianças como também com os acompanhantes, estimulando diversas técnicas lúdicas como: arteterapia, dramatizações e musicoterapia (Silveira \&Picollo, 2020).

$\mathrm{Na}$ arteterapia pode-se trabalhar com diversos materiais diferentes como papéis, dobraduras, lápis, hidrocor, giz de cera, pastel seco, tinta, pincéis, cola colorida, massinha de modelar, argila, sucata, materiais recicláveis, fantoches, máscaras, colagem, dentre outros. A sua aplicação oferece à criança a oportunidade de lidar melhor com as situações desfavoráveis que a mesma vivencia, estimulando seu desenvolvimento saudável, melhorando o humor e restabelecendo o seu equilíbrio emocional. Em relação às crianças que não conseguem ou não podem se comunicar verbalmente por algum motivo, artifícios como a pintura seria um dos grandes aliados para auxiliar na comunicação (Santos et al., 2017). 
$\mathrm{Na}$ brinquedoteca hospitalar devem existir tipos variados de brinquedos, como jogos de tabuleiros, de montar, bonecas, bolas, peças artesanais, educativas, bem como os brinquedos especiais ou adaptados para crianças com movimentos limitados devido à sua enfermidade, para crianças cegas, com dificuldades de fala e escuta, e até para crianças que estão em padrão de isolamento no hospital. As atividades especiais e as comemorações de datas festivas podem incluir um fundo educativo, envolvendo brindes e jogos que instiguem a participação delas nas celebrações. O grande objetivo destas atividades é o quebrar o ritmo normal da rotina diária impostas pelos procedimentos hospitalares (Silva et al., 2018).

A dramatização é um método que auxilia em diversas situações decorrentes da hospitalização. Segundo Caleffi et al (2016), em algumas atividades a criança pode até usar materiais como máscaras, aventais e luvas, para conseguir espelhar as condutas dos profissionais de saúde. Essa atividade possibilita compreender melhor os sentimentos das crianças internadas, pois retrata a situação que ela vivencia diariamente no hospital, a partir da sua própria percepção. A dramatização também é um meio muito eficaz para a aprendizagem, educação e promoção da saúde, visto que, através dela é possível representar visualmente diversas situações educativas, como: higiene bucal, lavagem das mãos, alimentação saudável, dentre outros (Martins et al., 2016).

A musicoterapia é uma forma de tratamento terapêutico que utiliza a música como instrumento na ajuda para o tratamento de patologias de etiologia física, emocional ou mental. A música consegue trabalhar os hemisférios cerebrais, promovendo equilíbrio entre o pensar e o sentir, trabalhando o emocional, a harmonia, o racional e a inteligência. A força do ritmo provoca respostas motoras, que, através da pulsação dá suporte para a improvisação de movimentos de expressão corporal e proporciona momentos de prazer ao paciente. Essa técnica também pode ajudar as crianças internadas nas formas de socialização, aumento da criatividade e relaxamento (Falke, Milbrath\&Freitag, 2018).

Avalia-se ainda que, o ambiente hospitalar pediátrico precisa contar também com profissionais de saúde com perfil para o setor, especialmente os da enfermagem, visto que a criança necessita de maior atenção e sensibilidade, sendo necessário aplicar uma forma de abordagem diferenciada do paciente adulto, de modo que as suas ações não se restrinjam somente às suas necessidades físicas e biológicas. Requer-se, portanto, que estes profissionais compactuem com todas as outras necessidades específicas da infância, e estabeleçam uma relação promotora de vínculos e confiança entre a criança e o seu acompanhante, vislumbrando a humanização e a promoção da saúde através do lúdico (Paula et al., 2019).

\section{Dificuldades e empecilhos que interferem na implantação da Ludoterapia}

Reconheceu-se, em diversos estudos que existem fatores que dificultam a aplicação da Ludoterapia, dentre eles destacase: a grande escassez de recursos/materiais/investimentos nas unidades hospitalares, sejam elas particulares ou públicas; a falta de apoio e sensibilidade da gestão em valorizar a importância de tais atividades; o medo das crianças em relação aos profissionais que impossibilita a aproximação devido à traumas já instalados; a falta de tempo e sobrecarga dos profissionais de saúde, dentre outros (Sabino et al., 2018).

Para Santos et al (2017), as instituições precisam começar a enxergar a brinquedoteca e o brinquedo terapêutico como peças obrigatórias e fundamentais no ambiente pediátrico, visto que muitas vezes as crianças são tratadas como adultos, sua singularidade e necessidade básica de brincar não é respeitada nem valorizada, e na maior parte das vezes elas acabam passando todo o período de internação sem nenhum contato com o lúdico, enraizando apenas memórias traumáticas e dolorosas durante o seu período no hospital.

Apesar de já ser considerado direito da criança pelo Estatuto da Criança e do Adolescente (ECA), a Lei Federal $n^{\circ}$ 11.104, datada de 21 de março de 2005, reafirma novamente em seus artigos que todos os hospitais que fornecem atendimento pediátrico deverão conter, obrigatoriamente, brinquedotecas em suas dependências, oferecendo um espaço provido de brinquedos e jogos educativos destinados a estimular as crianças e seus acompanhantes a brincarem. Entretanto, mesmo diante da obrigação instituída por lei, muitas vezes esse direito é negado (Costa \& Morais, 2017). 
Silva et al (2018), afirma que essa ferramenta não é utilizada pela equipe da pediatria devido à fatores como: falta de qualificação dos profissionais, bem como a falta de tempo devido ao quantitativo de profissionais reduzido e as inúmeras atribuições durante os plantões, muitas vezes também ocorre interdição da brinquedoteca por fatores estruturais, dessa forma, por não ser considerado um local prioritário na assistência e devido à falta de incentivo institucional há uma grande demora nas reformas e ajustes, o que contribui para a falta de espaço destinado à estas atividades, limitando a criança apenas ao leito de hospital.

Um dos fatores que desmotiva o uso da comunicação de formas lúdicas é o fato de que muitas unidades de tratamento ainda não apresentam ambientes específicos para o desenvolvimento de práticas ludoterápicas capazes de ofertar prazer à criança hospitalizada (Silva et al., 2019).

O estudo de Bosco et al (2019) também comprova que a falta de apoio institucional foi o principal obstáculo para a manutenção de recursos materiais na brinquedoteca, principalmente nos serviços que dependem unicamente de doações; além disso, a sobrecarga de trabalho da equipe de saúde também foi um dos principais fatores mencionados e mais preocupantes, visto que a quantidade reduzida de profissionais na equipe e o elevado número de atribuições que precisam ser realizadas, na maior parte vezes, toma todo o tempo do qual os profissionais dispõem para executar as práticas ludoterápicas.

Deste modo, considera-se primordial que os profissionais da pediatria desenvolvam estratégias para adquirir o apoio institucional, enfatizando sempre a importância deste local e das práticas lúdicas para a melhora e bem estar da criança e família, realizando abordagens teóricas baseadas em evidência para melhor credibilidade dos gestores, além de buscar participar frequentemente de atualizações e aperfeiçoamentos na área, com temas que contribuam para terapia da criança hospitalizada melhorando a assistência oferecida e tornando, assim, o atendimento pediátrico mais humano e qualificado (Caleffi et al., 2016).

\section{Estratégias para a introdução do lúdico no ambiente pediátrico}

Ainda hoje, a aplicação da abordagem lúdica apresenta inúmeras dificuldades, seja de recursos humanos, materiais ou estruturais. Porém, os empecilhos não devem justificar a privação do direito da criança de brincar e receber um cuidado mais humano e afetivo. Assim, é necessário que haja conscientização da equipe de saúde para que seja possível trabalhar com o lúdico mesmo quando todos os recursos são escassos, visando sempre o bem-estar e a aproximação com ela e a família. Santos et al (2017), afirmam que toda a equipe deve reconhecer o processo de brincar para a criança como sua principal atividade. Portanto, para isto a equipe precisa estar capacitada quanto à importância e o significado do ato de brincar, visando o respeito a esta necessidade nos serviços de saúde.

Do mesmo modo, há uma grande necessidade de apoio da instituição, para que esses profissionais consigam colocar em prática a abordagem lúdica na rotina de cuidados pediátricos, pois sabe- se que muitas vezes eles possuem muito pouco tempo e uma grande sobrecarga de atribuições para desempenhar todas as atividades assistenciais e os imprevistos que acontecem durante a jornada de trabalho. Reafirma-se também que é preciso um maior esforço por parte dos hospitais em promoverem uma reestruturação das suas unidades, melhorando sua infraestrutura nos espaços destinados às atividades ludoterápicas, e capacitando seus profissionais para um cuidado mais humano na pediatria (Silveira \&Picollo, 2020).

Os profissionais podem ser estimulados a introduzir o lúdico no cuidado à criança, através de palestras, oficinas ou outra metodologia que proporcione o aprendizado, contribuindo para demonstrar seu papel de grande relevância para os pacientes. No entanto, é importante que este estímulo ocorra desde o processo de formação, como importante estratégia para a conscientização e melhoria da qualidade do cuidado à criança hospitalizada, ampliando os conhecimentos sobre as práticas lúdicas ainda na graduação (Falke, Milbrath\&Freitag, 2018).

Reforça-se ainda que, se autorizado pela instituição, possuir voluntários e universitários também é uma ótima opção, pois além de não possuir custo existe a contribuição mútua de aprendizado para eles e diversão para as crianças. É importante 
frisar ainda, sobre o uso de roupas coloridas, adereços e fantasias na pediatria, visto que, o uso de vestimentas e jalecos coloridos ajuda a amenizar o medo que as crianças têm dos profissionais que as assistem, e muitas vezes as mesmas interagem com os desenhos e figuras das roupas, dessa forma, os profissionais auxiliam a criança a sentir-se bem apenas com uma pequena mudança no vestuário (Paula et al., 2019).

Considera-se também, o uso de equipamentos eletrônicos como uma importante estratégia lúdica para as crianças que estão restritas ao leito, com algum equipamento que as impossibilitam de se movimentar, restrição de movimentos, ou quando se encontram fadigadas e sem ânimo, preferindo fazer atividades mais fáceis, que não exijam esforço físico e não haja a necessidade de sair do leito, principalmente no caso de pacientes ortopédicos e oncológicos. A depender do caso, também pode ser solicitado à família para trazer os brinquedos preferidos da criança, DVD's, ou computador, para ajudá-las a enfrentar esse processo, entretendo-as e distraindo-as com mais facilidade (Silva et al., 2018).

Por fim, é importante frisar que o lúdico não deve ser inserido em um único momento durante a internação, mas em toda rotina hospitalar com a criança, e em todas as vezes que for necessário manter a comunicação com ela, inclusive quando for preciso administrar medicamentos ou realizar procedimentos, solicitando sempre a sua permissão de forma carinhosa e explicando o passo a passo de tudo que será realizado, utilizando preferencialmente o auxílio de brinquedos terapêuticos, como bonecos e fantoches para melhor representação visual, de forma que ela compreenda a sua finalidade e se sinta segura com a equipe de saúde (Martins et al., 2016).

\section{Conclusão}

É inegável que a hospitalização interfere na qualidade de vida e bem-estar da criança. Visto que, brincar é essencial durante esta fase, pois além de proporcionar diversão, alegria e socialização, também contribui para a sua aprendizagem e desenvolvimento. Portanto, a ludoterapia aparece neste cenário como uma mediadora entre o processo de enfrentamento da enfermidade e a continuidade da infância mesmo no ambiente hospitalar, possibilitando à criança um meio ao qual ela poderá se aproximar de sua vida "normal" e continuar desenvolvendo suas brincadeiras, tanto sozinha, quanto acompanhada, sendo de grande ajuda para superar os problemas adquiridos neste período de internação.

Entretanto, mesmo sabendo da importância das práticas lúdicas no tratamento infantil e da sua obrigatoriedade nos ambientes pediátricos, esta revisão bibliográfica evidenciou que na grande maioria dos estudos ainda há uma grande desvalorização desta atividade, tanto pelos profissionais quanto pelas instituições, que não fornecem apoio, investimento ou incentivo para a inclusão desta prática na rotina de cuidados assistenciais da criança. Deste modo, os momentos lúdicos são sempre deixados em segundo plano e o paciente pediátrico acaba adquirindo apenas experiências negativas durante a sua internação, colecionando diversos traumas que interferem na sua vida pós-alta e gerando insatisfação nos pais.

Da mesma forma, é preciso que haja maior capacitação dos acadêmicos e profissionais da área, para que a ludoterapia seja vista como algo inerente e inseparável da assistência infantil, e funcione de forma mais efetiva. Visto que, o lúdico traz benefícios não somente para a criança que está internada, mas, também, para o seu acompanhante, para a instituição e para a equipe de saúde que está prestando a assistência, propiciando, assim, um atendimento pediátrico mais humano e qualificado.

Notou-se ainda que, existe uma grande limitação e escassez de pesquisas voltadas para este tema, reforçando a necessidade de maior investimento e conhecimento técnico-científico no que refere a esta prática nas unidades de internação infantil. Deste modo, enfatiza-se a necessidade de novos estudos que debatam mais sobre essa temática, a fim de aumentar a atenção do público-alvo para esta problemática e ampliar o número de pesquisas e intervenções mais atualizadas e com maiores evidências, facilitando a implantação das práticas lúdicas nestes ambientes, como sugestão para um trabalho futuro, está em elencar a participação dos profissionais de enfermagem em práticas ludoterápicas no âmbito hospitalar. 
Research, Society and Development, v. 10, n. 8, e31010817309, 2021

(CC BY 4.0) | ISSN 2525-3409 | DOI: http://dx.doi.org/10.33448/rsd-v10i8.17309

\section{Referências}

Bosco, E. B. D. et al. (2019). Humanização hospitalar na pediatria: Projeto “Enfermeiros da Alegria”. Revista de Enfermagem UFPE. 13(4), 1173-8.

Coelho, L. S. G. (2016). Recusa escolar: um Estudo de Caso em Ludoterapia Comportamental. Psicologia: Ciência e Profissão. 36(1), 234-245.

Caleffi, C. C. S. et al. (2016). Contribuição do brinquedo terapêutico estruturado em um modelo de cuidado de enfermagem para crianças hospitalizadas. Revista Gaúcha de Enfermagem. 37(2), 58-69.

Costa, T. S. \&Morais, A. C. (2017). A hospitalização infantil: Vivência de crianças a partir de representações gráfica. Revista de Enfermagem UFPE, 11(1), 358-367.

Falke, A. C. S., Milbrath, V. M. \&Freitag, V. L. (2017). Percepção da equipe de enfermagem sobre a abordagem lúdica à criança hospitalizada. Cultura de Los Cuidados. 22(50), 12-24.

Fioreti, F. C. C. F., Manzo, B. F. \& Regino, A. E. F. (2016). A Ludoterapia e a criança hospitalizada na perspectiva dos pais. Revista Mineira de Enfermagem. 20(09), 97-104.

Júnior, A. M. F. et al. (2019). A importância do brincar durante a internação hospitalar: um relato de experiência. Revista Eletrônica Acervo Científico, 5 , e1315.

Lemos, I. C. S. et al. (2016). Brinquedo terapêutico no procedimento de punção venosa: Estratégia para reduzir alterações comportamentais. Revista Cuidarte. 07(01), 1163-1170.

Martins, A. K. L. et al. (2016). Repercussões da clownterapia no processo de hospitalização da criança. Revista de pesquisa cuidado é fundamental. 08(01), 3968-3978.

Paula, G. K. et al. (2019). Estratégias lúdicas no cuidado de enfermagem à criança hospitalizada. Revista de Enfermagem UFPE. 13(23), 79-89.

Sabino, A. S. et al. (2018). O conhecimento dos pais quanto ao processo do cuidar por meio do brincar. Cogitare Enfermagem. 23(02), 81-89.

Santos, S. S. et al. (2017). A Ludoterapia como ferramenta na assistência humanizada de enfermagem. Revista Científica de Enfermagem. 07(21), 30-40.

Silva, D. O. et al. (2018). A importância do lúdico no contexto da hospitalização infantil. Revista de Enfermagem UFPE. 12(12), 3484-3491.

Silva, E. M. G. et al. (2019). Contribuições Da Ludoterapia Para Crianças Hospitalizadas, IV Jornada Acadêmica do Hospital Universitário Professor Alberto Nunes. 2(2), 505-511.

Silva, J. M. L., et al (2020). O brinquedo terapêutico instrucional como ferramenta na assistência oncológica infantil. Research, Society and development. 9(7), e408974253.

Silva, M. K. C. O. S. et al. (2019). A utilização do Lúdico no Cenário da Hospitalização Pediátrica. Revista de Enfermagem UFPE. 13(01), 117-126.

Silva, R. D. M., et al. (2017). Therapeutic play to prepare children for invasive procedures: a systematic review. Jornal de Pediatria. 93(1), 6-16.

Silva, S. G. T. S. et al. (2017). Influência do Brinquedo Terapêutico na ansiedade de crianças escolares hospitalizadas: Ensaio clínico. Revista Brasileira de Enfermagem, São Paulo, 70(06), 1314-1319.

Silva, S. R. M. et al. (2018). Percepção dos acompanhantes das crianças hospitalizadas acerca do brinquedo terapêutico. Revista de Enfermagem UFPE. 12(10), 2703-2709.

Silveira, A. \& Picollo, B. M. (2020). Brinquedo Terapêutico na assistência à criança hospitalizada na voz dos profissionais de enfermagem. Revista Espaço Ciência e Saúde. 08(02), 51-60. 